\title{
THE VARIATION OF STRAIN RATIO AT THE TENSILE TEST DESCRIBED BY A HYPERBOLIC FUNCTION
}

\author{
W. TRUSZKOWSKI ${ }^{1}$ and J. KLOCH ${ }^{2}$ \\ ${ }^{I}$ Aleksander Krupkowski Institute of Metallurgy and Materials Science of Polish \\ Academy of Sciences, ul. Reymonta 25, 30-059 Kraków, POLAND \\ ${ }^{2}$ Institute of Mathematics of Polish Academy of Sciences, ul. Sw. Tomasza 30, \\ 31-027 Kraków, POLAND
}

(Received 5 November 1995)

\begin{abstract}
The function describing the variation of plastic anisotropy $r$ at the uniaxial deformation $\varepsilon$ is a compendium of knowledge on polycrystalline metals subdued to plastic working. In real single crystals $r(\varepsilon)$ function characterizes the degree of imperfection of the crystallographic orientation ("texture of a single crystal"). It has been shown that the best fitting function of the $r-\varepsilon$ relationship for single crystals as well as for polycrystalline metals is that based on a hyperbolic function.
\end{abstract}

KEY WORDS: Anisotropy, crystallographic orientation, mechanical properties, single crystals.

\section{INTRODUCTION}

Plastic anisotropy is described by the strain ratio $r$ as proposed by Krupkowski and Kawiński (1949) or Lankford, Snyder and Bauscher (1950). In both methods the $r$ value is experimentally determined in the tensile test on a test piece deformed up to a considerable strain (e.g. at the limit of uniform elongation). Therefore, the authors were implicitly assuming that the strain ratio does not change at the tensile test which, however, is true only in some special cases e.g. in deep drawn mild steels. And it was only six years later that Truszkowski (1956) observed in the research on anisotropy of polycrystalline nickel, the variation of strain ratio with the tensile deformation. The research has been continued by several authors on f.c.c. and b.c.c. polycrystalline metals and single crystals (e.g. Truszkowski and Jarominek (1973), Truszkowski (1976, 1984, 1988), Hsun Hu (1975a, 1975b)), Bunge et al. (1981). In the present authors' opinion the generally used value of the strain ratio calculated at the limit of uniform elongation $r_{a}$ well describes the directionality for industrial purposes e.g. for the estimation of the deep drawability of metal sheets. However, the $r_{a}$ value does not describe the intrinsic property of the material as being changed during the process itself of the tensile test. On the other hand the $r(\varepsilon)$ function illustrates the variation of $r$-coefficient with strain and the $r_{o}$ value is calculated by the back extrapolation of the $r(\varepsilon)$ up to $\varepsilon=0$ $\left(r_{o}=r(0)\right) ; r_{o}$ is the intrinsic property with precisely determined physical meaning.

In general cases the form of the $r(\varepsilon)$ function is not known, therefore the $r_{o}$ value calculated by the extrapolation method requires the verification of its physical meaning. Additionally, the experimentally determined $r(\varepsilon)$ function is characterised by the large 
scatter of data, which is asymmetric and strongly varying with the elongation: small at large strain, rising with diminishing deformation and very high when $\varepsilon$ tends to zero. All the mentioned difficulties gave the reasons for elaborating mathematical method aiming at precise determination of the $r_{o}$ value; very useful was a number of experimental data on single crystals and polycrystalline metals which allowed to suggest the general form of the $r=f(\varepsilon)$ function.

\section{DETERMINATION OF THE $r(\varepsilon)$ FUNCTION FROM EXPERIMENTAL DATA}

Statistical analysis of scatter of experimental data around the $r(\varepsilon)$ function at the assumed value of the experimental error $c_{o}$ (while $c$ is varying with the elongation: $c(\varepsilon)$ ) made possible the calculation of the $r^{-}(\varepsilon)$ and $r^{+}(\varepsilon)$ functions which describe the lower and upper limits of the zone of scatter, (Truszkowski and Kloch $(1985,1986)$, Kloch and Truszkowski (1986)). When the deformation is macrohomogeneous $(c(\varepsilon)=$ const. $=c_{o}$ ) the range of scatter, which is large at small strains rapidly diminishes with deformation. The macroinhomogeneous deformation provokes the rising of the range of the scatter even at medium strains. This is illustrated by the diagrams in Figures

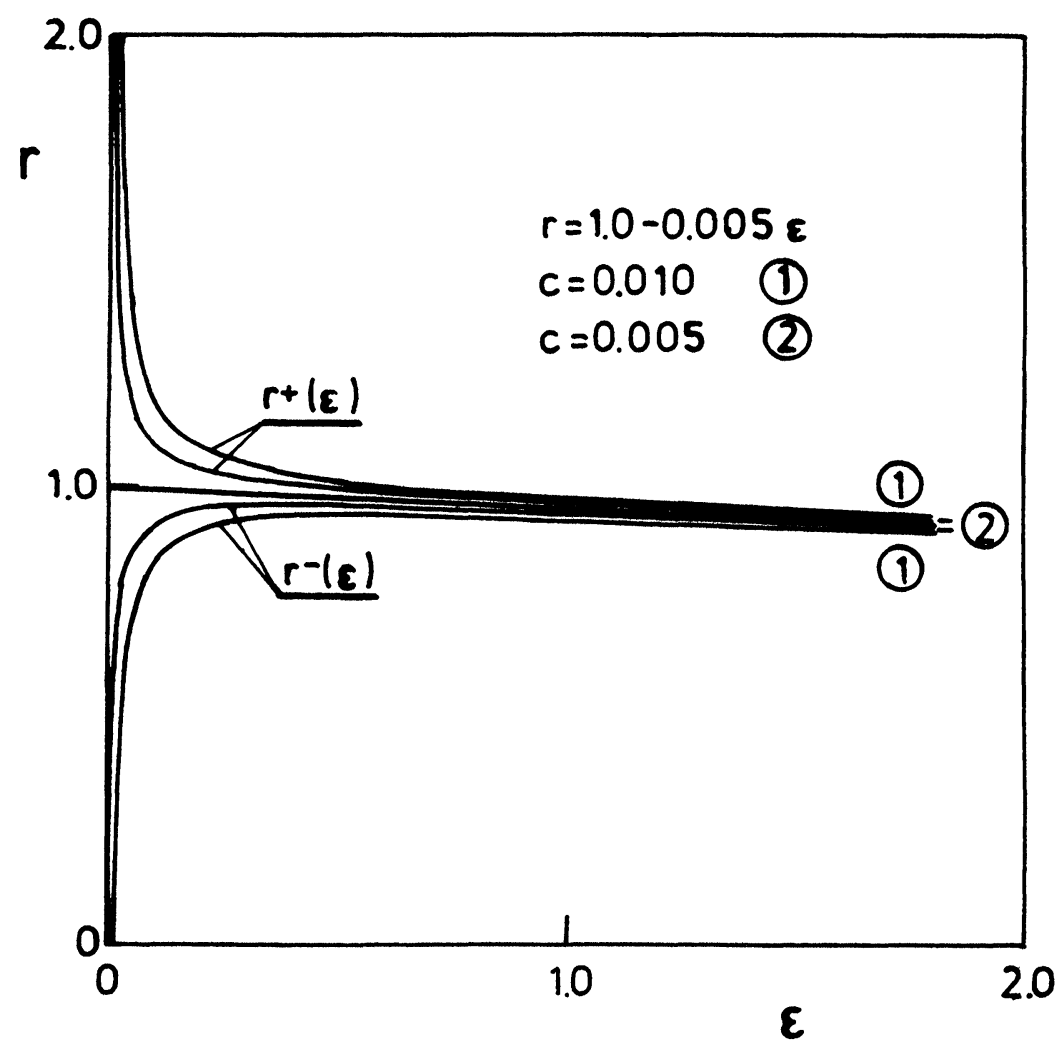

Figure 1 Effect of experimental error $c$ on the scatter of results around the function $r=1.0-0.05 \varepsilon$. Macrohomogeneous deformation. 
1 and 2. The $r(\varepsilon)$ and $c(\varepsilon)$ diagrams were assumed in the following form: $r=1.0$ - $0.05 \varepsilon$, while for homogenous deformation: $c=0.010$ for (1) and $c=0.005$ for (2), and for inhomogeneous deformation: $c=0.010+0.32 \varepsilon$ for (1) and $c=0.01+0.03 \varepsilon$ for (2). (Similar characteristics for $r$ and $\varepsilon$ were obtained in the experimental research on the polycrystalline copper). The lower and upper limits of the range of experimental scatter $\left(\bar{r}(\varepsilon)\right.$ and $\left.r^{+}(\varepsilon)\right)$ embrace all experimental points $\left(\varepsilon_{i}, r_{i}\right)$ and make possible, with the use of elaborated program, the calculation of the $r(\varepsilon)$ and $c(\varepsilon)$ functions. It is the $c(\varepsilon)$ function which characterizes the macroinhomogeneity of deformation at the tensile test.

To illustrate the described maximum error method of the determination of the fitting function, two examples of the $r(\varepsilon)$ and $c(\varepsilon)$ functions for the $81 / 19$ brass in the cold rolled state $(40.5$ pct of the rolling reduction) and in the annealed state are presented in Figures 3 and 4 . In both cases the $r^{-}(\varepsilon)$ and $r^{+}(\varepsilon)$ functions include all experimental data, while the variation of the coefficient with the strain describes the inhomogeneity of deformation.

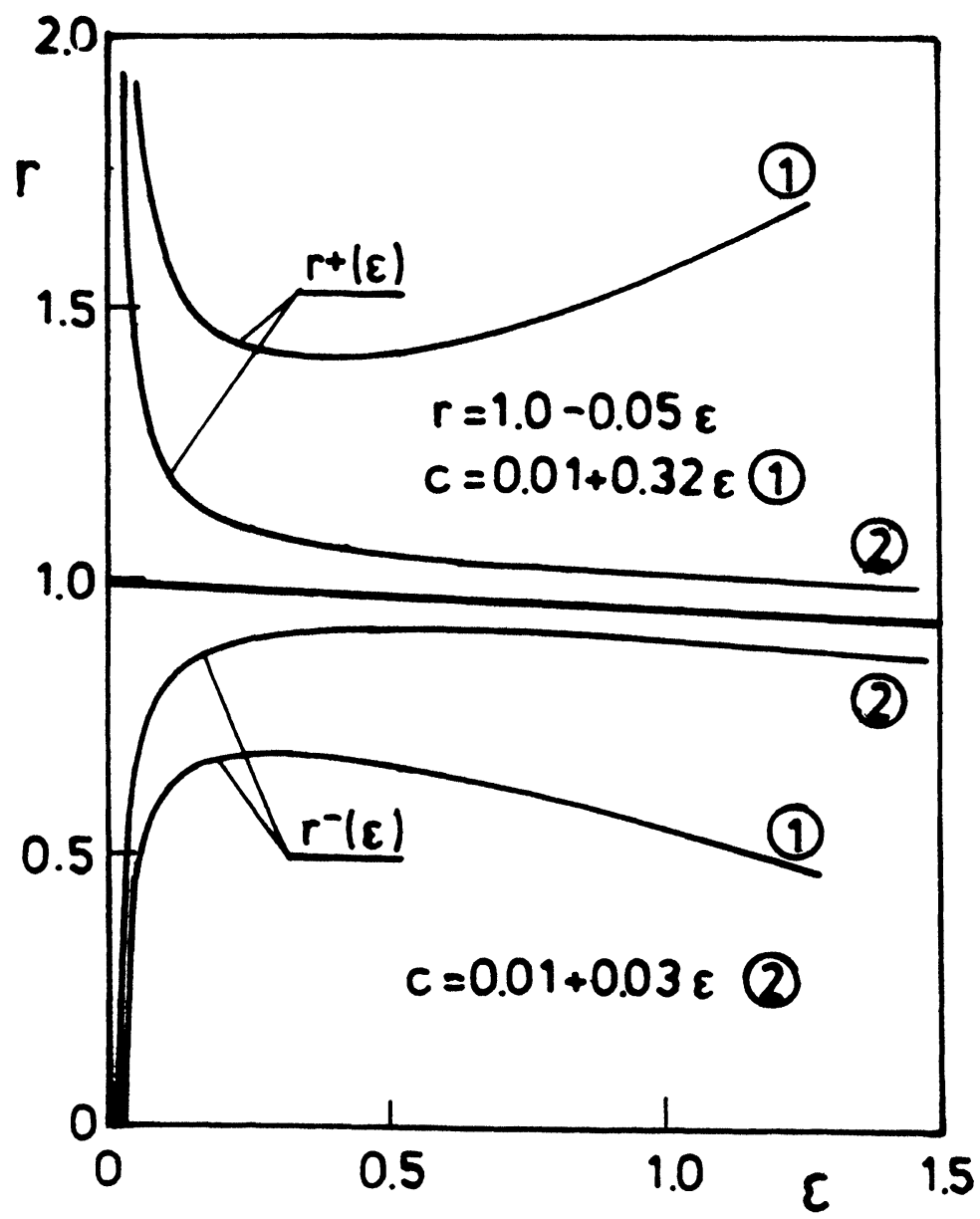

Figure 2 Effect of experimental error $c$ on the scatter of results around the function $r=1.0-0.05 \varepsilon$. Macroinhomogeneous deformation. 


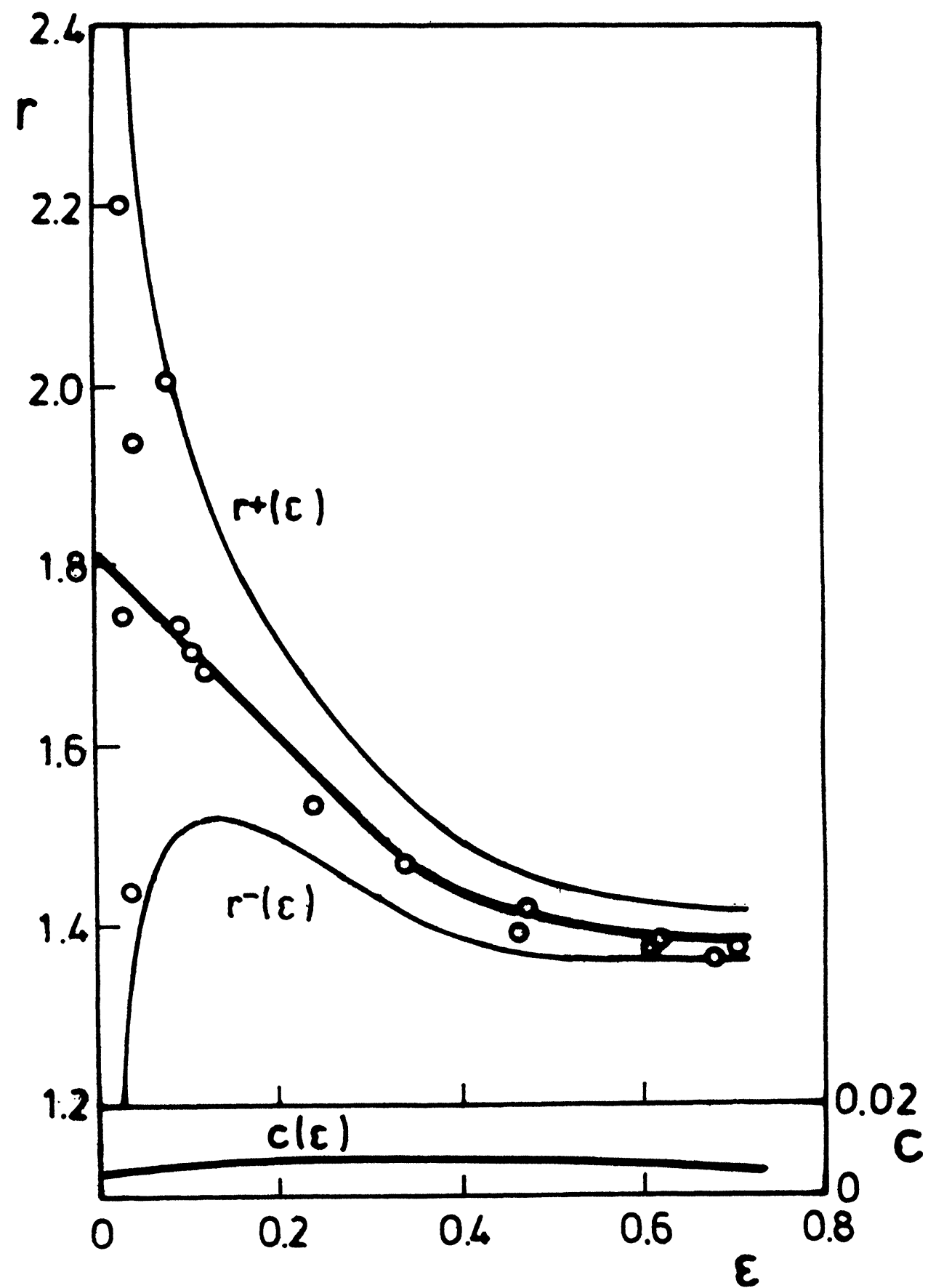

Figure $3 r^{-}(\varepsilon), r(\varepsilon)$ and $r^{+}(\varepsilon)$ relationships of the cold rolled $81 / 19$ brass (40.5 pct rolling reduction). Experimental data from: Truszkowski, Dutkiewicz, Szpunar (1970). 


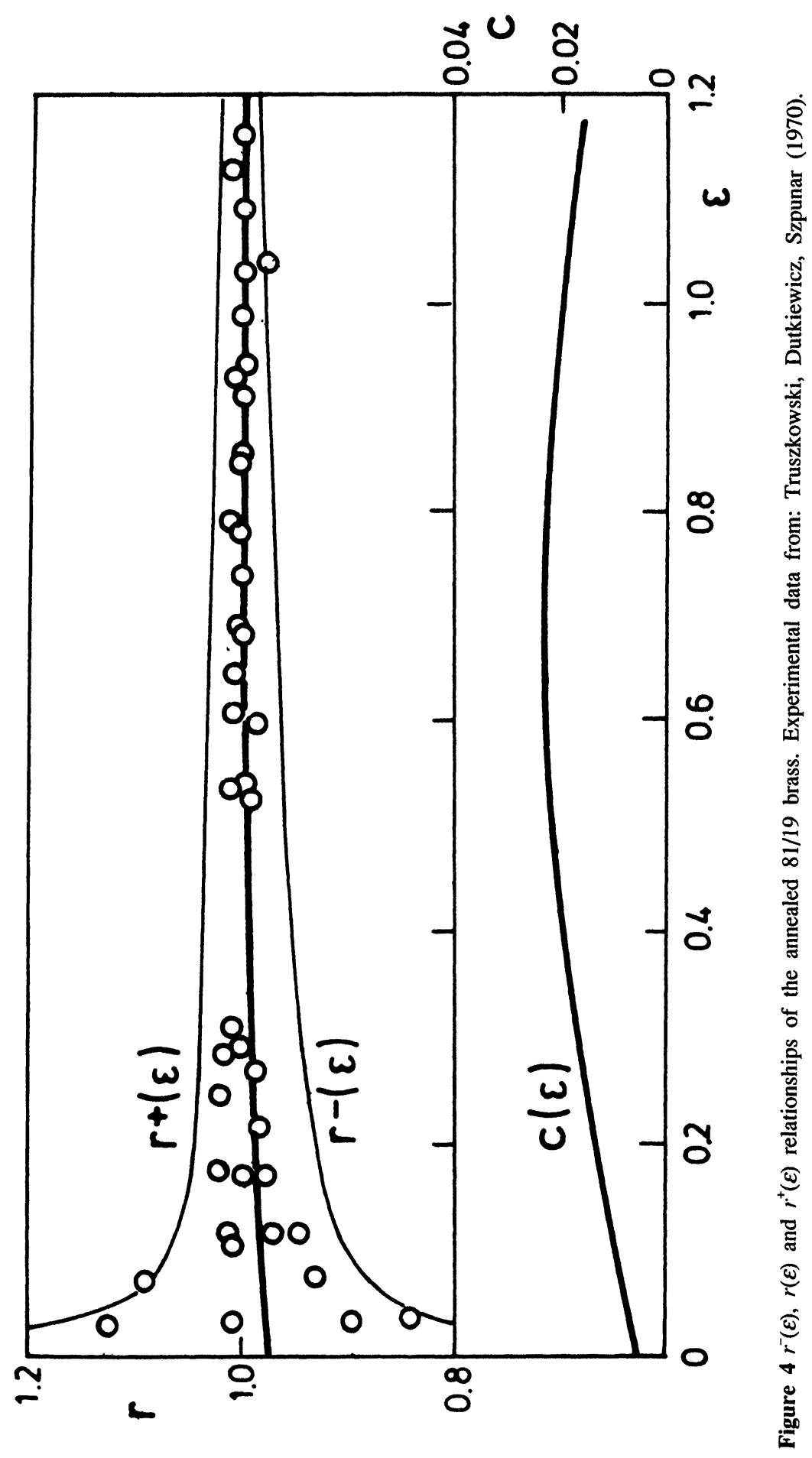




\section{THE GENERAL FORM OF THE $r(\varepsilon)$ FUNCTION}

Plastic deformation at the tensile test of the metal sample with the random crystallographic orientation induces the formation of texture which reproduces the symmetry of the deformation process: the sample axis is the axis of symmetry of the forming texture. It has been shown in experiments that in case of random (or closeto-random) orientation $r(\varepsilon)$ is a linear function, the $r_{o}$ value being close to 1 ; this can be illustrated on example of recrystallized nickel in the close-to-isotropic state, and annealed copper for which the X-ray diffraction revealed almost random orientation (Figures 5 and 6).

A similar behaviour is observed in single crystals with highly ordered, symmetric crystallographic orientation. Figures 7 and 8 present $r-\varepsilon$ relations of the [001] copper crystal grown by the Bridgman method and [011] nickel crystal produced using the method of Czochralski (Truszkowski and Wierzbiński (1983), Truszkowski et al. (1987)). If, however, the sample of the metal with sharp texture and the coefficient $r_{o}$ differing much from the value 1 (e.g. the hot-rolled nickel which $r(\varepsilon)$ function is shown in Figure 9) is subdued to tensile test, the $r-\varepsilon$ diagram exhibits two zones: (1) increase in $r$ to attain the value $r \sim 1$, and (2) slow diminishing of the strain ratio $r$. It is characteristic that in both zones $r(\varepsilon)$ function can be described by the straightlinear function; its slope in the first zone is $n_{1}$ while in the second $n_{2}$, the transition from $n_{1}$ to $n_{2}$ occurs in a continuous way in the (1)-(2) zone. The $r(\varepsilon)$ function of the polycrystalline nickel, described above, illustrates well the variation of the strain ratio with the elongation in the tensile test, independently of whether in the first zone one observes the increase or decrease of the $r$ value.

Analogically, two zones in the $r-\varepsilon$ curve can be observed in the process of straining of a single crystal in which crystal orientation deviates from the symmetrical one. Figure 10 presents the $r-\varepsilon$ relationship for the $\mathrm{CuZn10-4^{ \circ }}$ [011] brass single crystal (the [011] direction deviated from the sample axis by $4^{\circ}$ in the $\{001\}$ plane): the rapid, closeto-linear, drop of $r$ with $\varepsilon$ up to about $\varepsilon=0.004$ followed by slow, equally linear diminishing of $r$ values within zone $\varepsilon>0.02$, and continuous variation of the slope of the $r(\varepsilon)$ function in a transition zone $0.004<\varepsilon<0.02$. Such a variation of the strain ratio with strain has suggested to the authors the description of the $r(\varepsilon)$ function by a hyperbola.

The equation of the hyperbola defined for all $\varepsilon \in \mathrm{R}$ has the form:

if only:

$$
r=a_{1} \varepsilon+a_{2}+a_{3}\left(\varepsilon^{2}+a_{4} \varepsilon+a_{5}\right)^{1 / 2}
$$

$$
a_{4}^{2}-4 a_{5} \leq 0
$$

The equations of asymptotes are:

$$
\begin{aligned}
& r=\left(a_{1}+a_{3}\right) \varepsilon+a_{2}+0.5 a_{3} a_{4} \\
& r=\left(a_{1}-a_{3}\right) \varepsilon+a_{2}-0.5 a_{3} a_{4}
\end{aligned}
$$

and the point of their intersection is:

$$
P_{1}\left(\varepsilon_{1}, r_{1}\right)=\left(-0.5 a_{4}, a_{2}-0.5 a_{1} a_{4}\right)
$$


THE VARIATION OF STRAIN RATIO

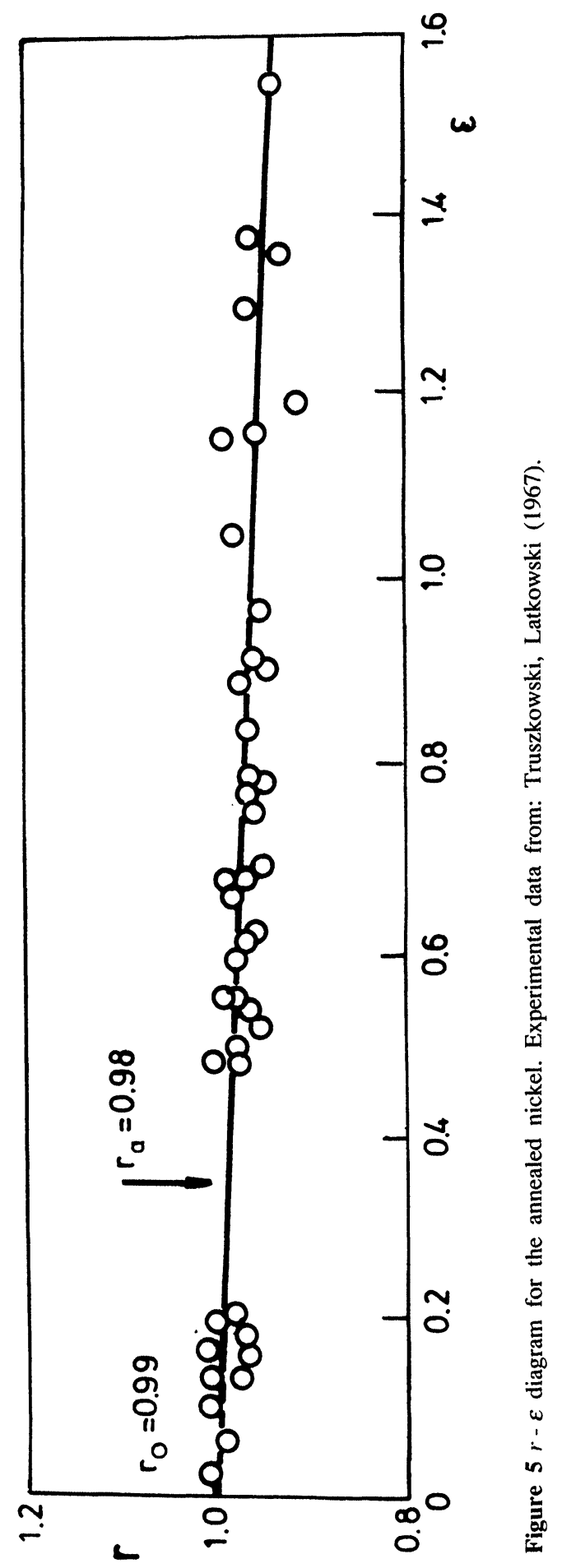




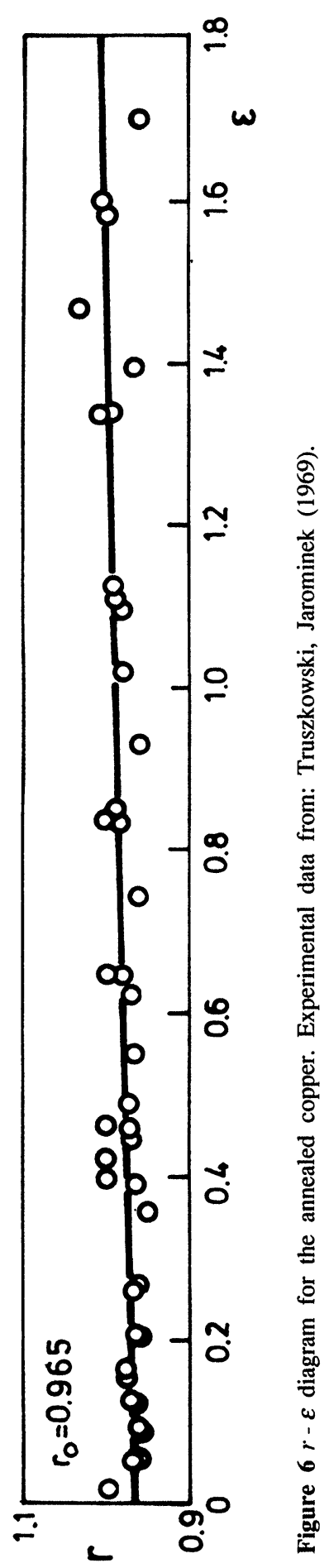




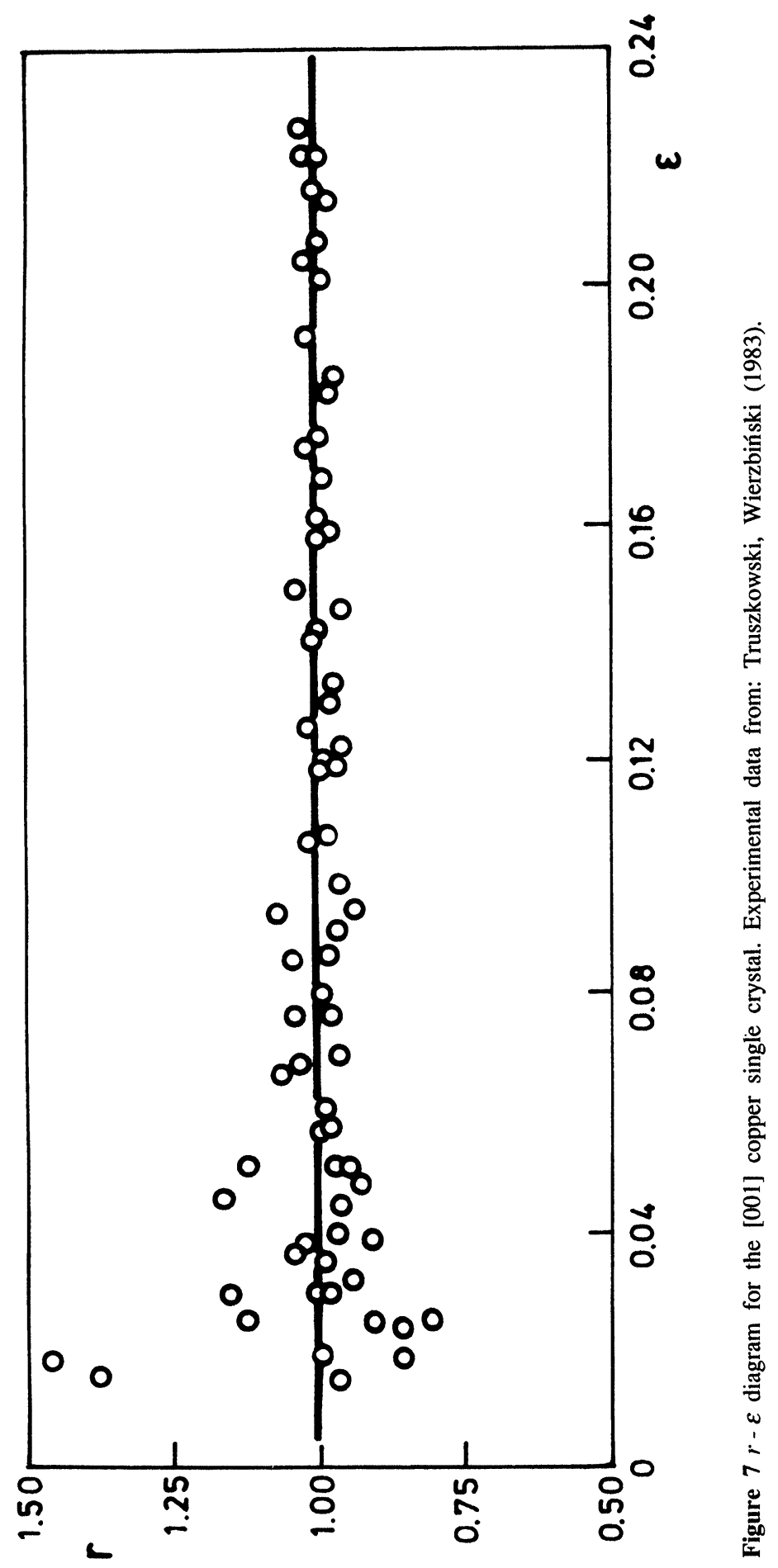




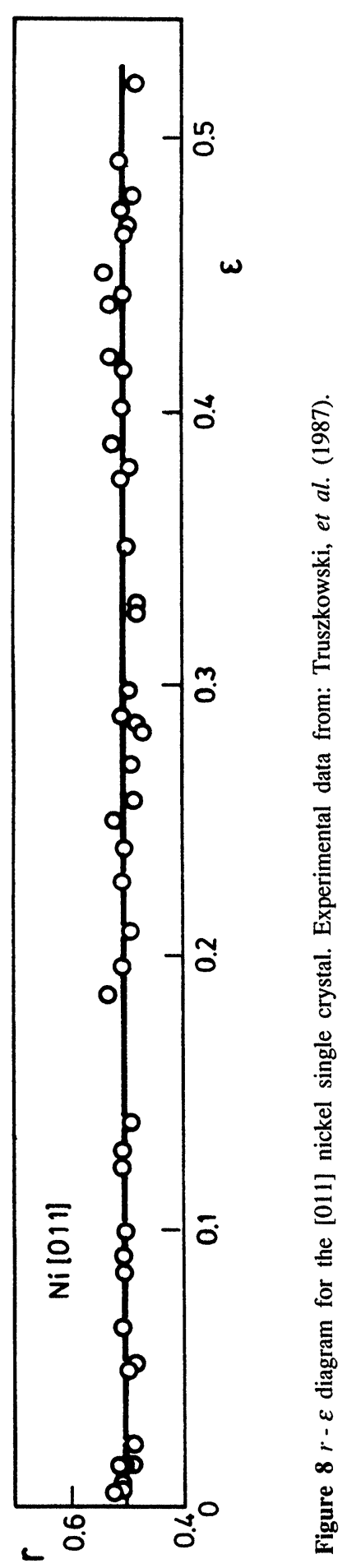




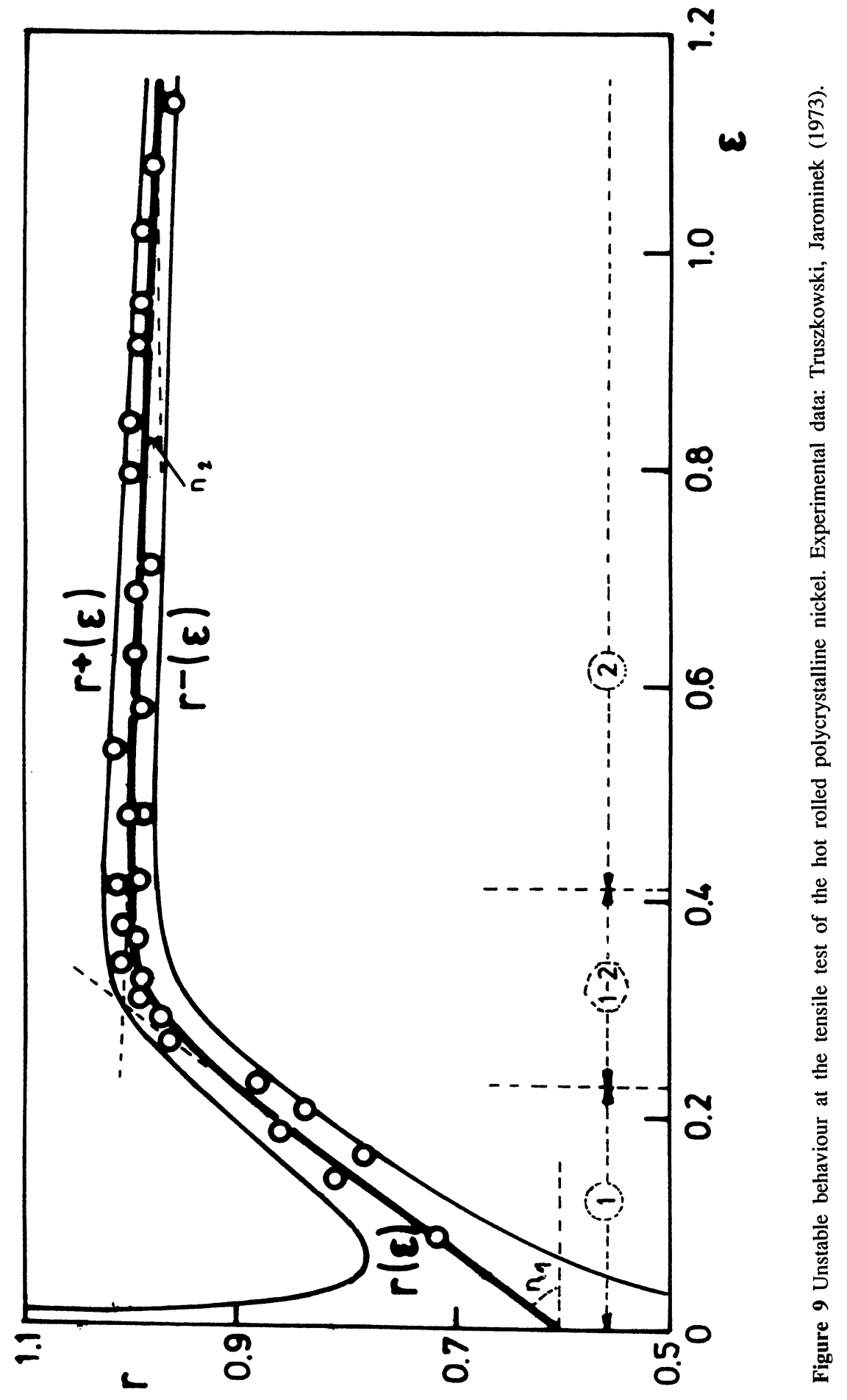




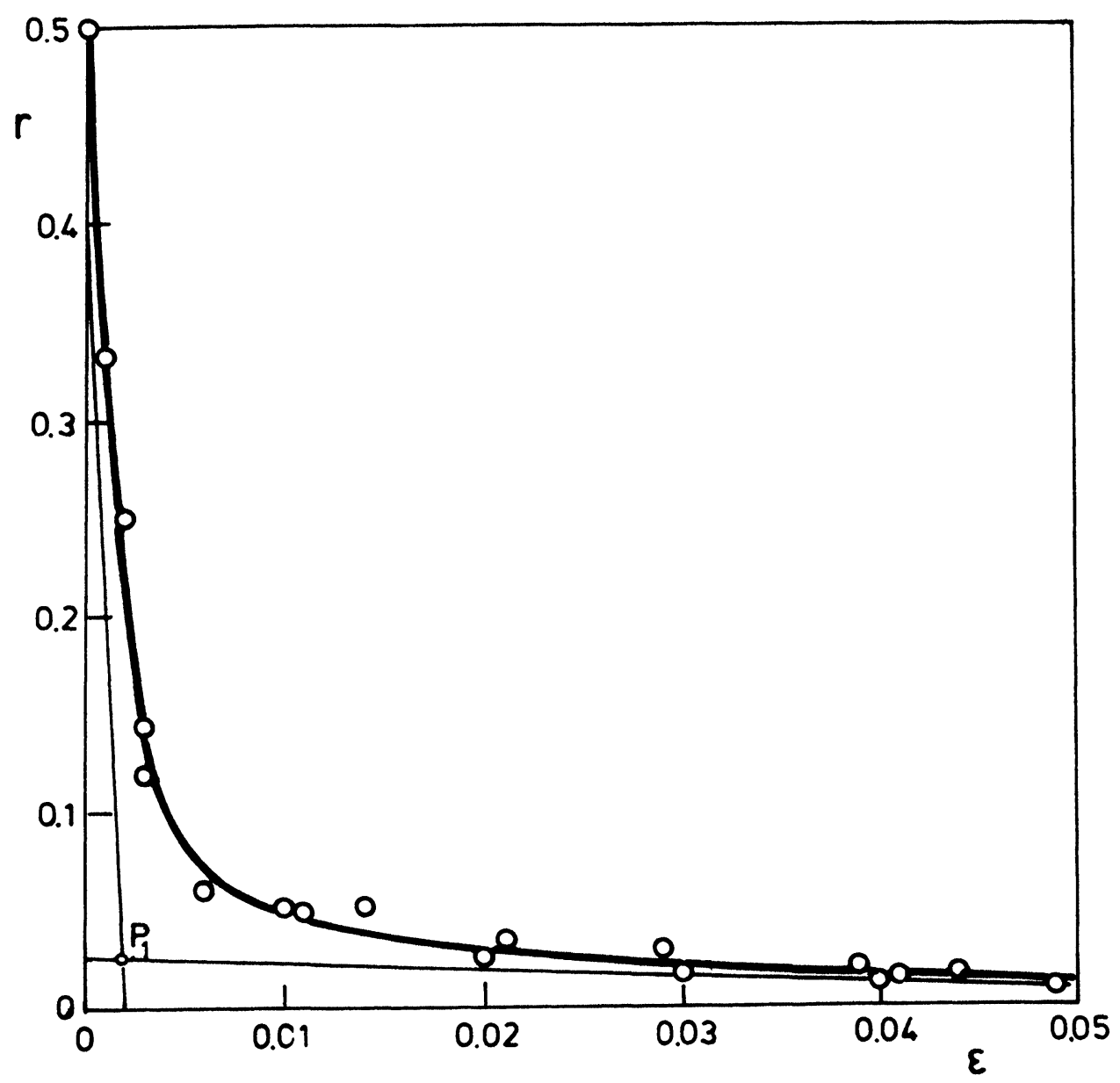

Figure 10 Unstable behaviour at the tensile tested $4^{\circ}$ [011] CuZu10 brass single crystal. Experimental data: Truszkowski, Kloch (1989).

\section{EXPERIMENTAL VERIFICATION}

\section{SINGLE Crystals}

Single crystal of $10 \mathrm{wt}$ pct $\mathrm{Zn}$ brass with the orientation $4^{\circ}$ [011] (mentioned in the preceding chapter) has been tensile tested up to the elongation $\varepsilon=0.05$ (Figure 10).

The parameters of the equation (1) calculated for the tested brass with the least square method are: $a_{1}=-102.09, a_{2}=0.2209, a_{3}=101.73, a_{4}=-3.810^{-3}, a_{5}=7.510^{-6}$.

Consequently, the asymptotes are

$$
\begin{aligned}
& r=-0.3577 \varepsilon+0.0269, \\
& r=-203.88 \varepsilon+0.4151
\end{aligned}
$$

and their intersection point $P_{1}\left(\varepsilon_{1}, r_{1}\right)=(0.002,0.026)$. 
It can be seen that the hyperbola (1) proposed for the description of results plotted in the $r(\varepsilon)$ relationship fits well to the experimental points (Figure 10). For $\varepsilon=0$ the value $r_{0}=r(0)$ is equal to 0.5 which is a perfect agreement with the theoretically calculated value $r_{0[011]}=0.5$ (Truszkowski (1984)).

The diagram in Figure 11 shows the $r-\varepsilon$ relationship of the CuZn10 [011] brass single crystal. Here in spite of a considerable scatter of experimental data in the zone of small deformations, the determined with the aid of maximal errors method (Truszkowski and Kloch $(1985,1986)) r_{\circ}$ value is equal to that calculated theoretically $r_{\text {o[011] }}=0.5$.

Equally good fitting by the hyperbolic equation (1) of experimental data from the tensile testing of the [011] copper single crystal is observed in Figure 12.

\section{POLYCRYSTALS}

Several test pieces of polycrystalline f.c.c. metals and alloys have been strained up to the instability limit and the hyperbolic fitting function was calculated using the above described method. Two examples presented in this paper (Figures 3 and 4) evidence the correct approximation of the $r-\varepsilon$ data by the hyperbolic function. All $r(\varepsilon)$ functions have been calculated using the earlier proposed method of the fitting function based on the concept of maximal error.

\section{CONCLUSIONS}

The most important papers on plastic anisotropy which appeared recently are these which contribute to the determination of the relation between directionality of physical characteristics, crystallographic texture and material properties. Both their fundamental and technological aspects aim at the improvement of testing methods and amelioration of deep drawability by varying texture and work hardening ability of metal sheets.

The $r(\varepsilon)$ function which describes the variation of plastic anisotropy at the uniaxal deformation is a rich source of information on polycrystalline metals subdued to the process of plastic working. In real single crystals the $r(\varepsilon)$ function is the basis for the determination of the degree of the imperfection of crystallographic orientation (degree of texture), this property being of importance in evaluating the instability of orientation in deformed crystals.

It has been shown in the paper that in spite of large and asymmetric scatter of experimental $\left(\varepsilon_{i}, r_{i}\right)$ data, the proper interpretation of the variation of the strain ratio in deformed metals is obtained by the application of the authors' method of determination of the fitting function based on maximal errors and the description of the $r(\varepsilon)$ function by the hyperbolic equation (1).

\section{References}

Bunge, H. J., Grzesik, D., Ahrndt, G. and Schulze, M. (1981). The relation between preferred orientation and the Lankford Parameter $r$ of plastic anisotropy. Arch. Eisenhüttenwes., 52, 407-411.

$\mathrm{Hu}$, Hsun (1975a). The Strain Dependence of Plastic Strain Ratio ( $r_{m}$ value) of Deep Drawing Sheet Steels Determined by Simple Tension Test. Metall. Trans., 6A, 945-947.

$\mathrm{Hu}$, Hsun (1975b). Effect of Plastic Strain on the $r$ - Value of Textured Steel Sheet. Metall. Trans., 6A, 2307-2309.

Kloch, J. and Truszkowski, W. (1986). The Method of Determination of the Fitting Function Based on Maximal Errors. Bull. Pol. Ac.: Techn., 34, 683-690. 


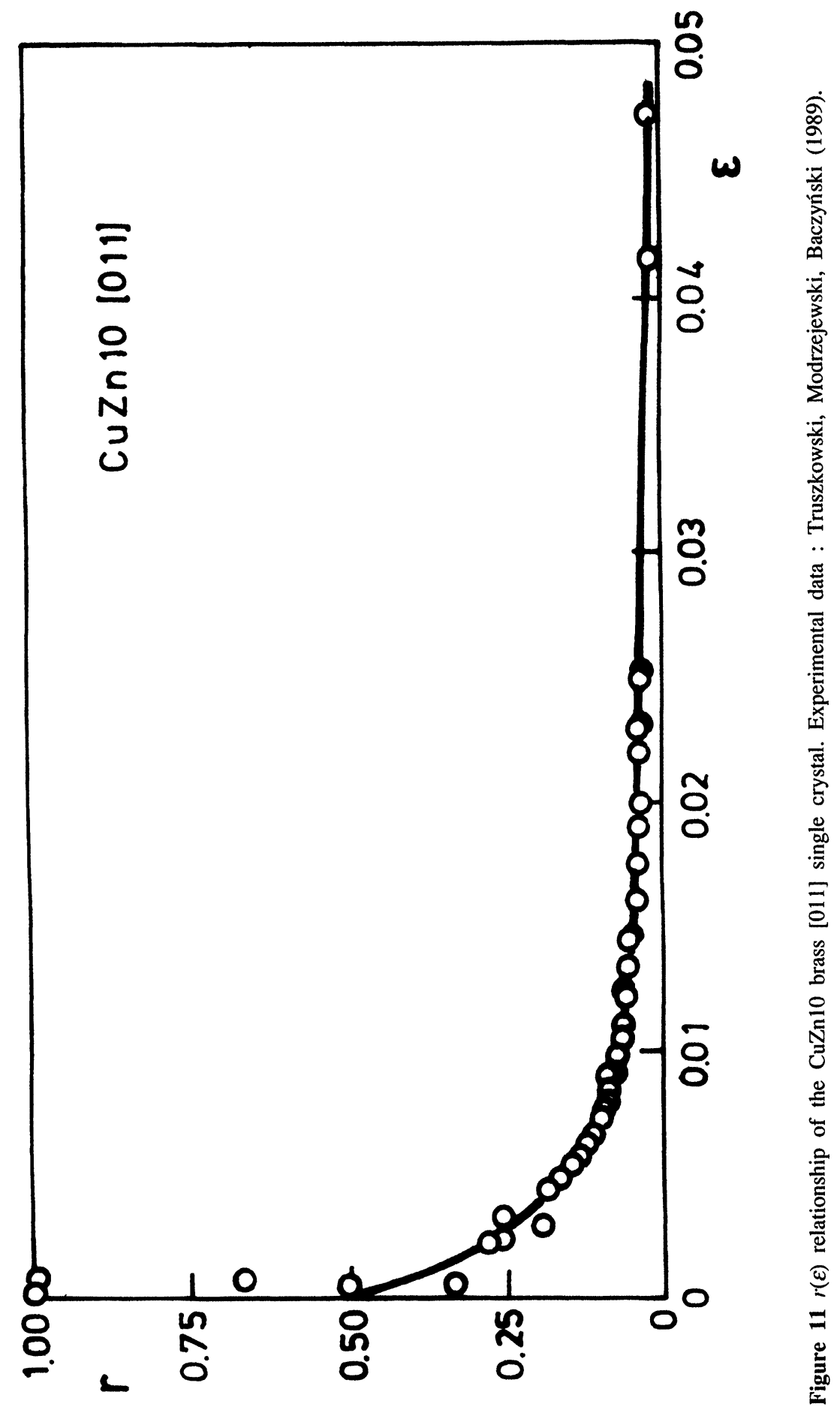




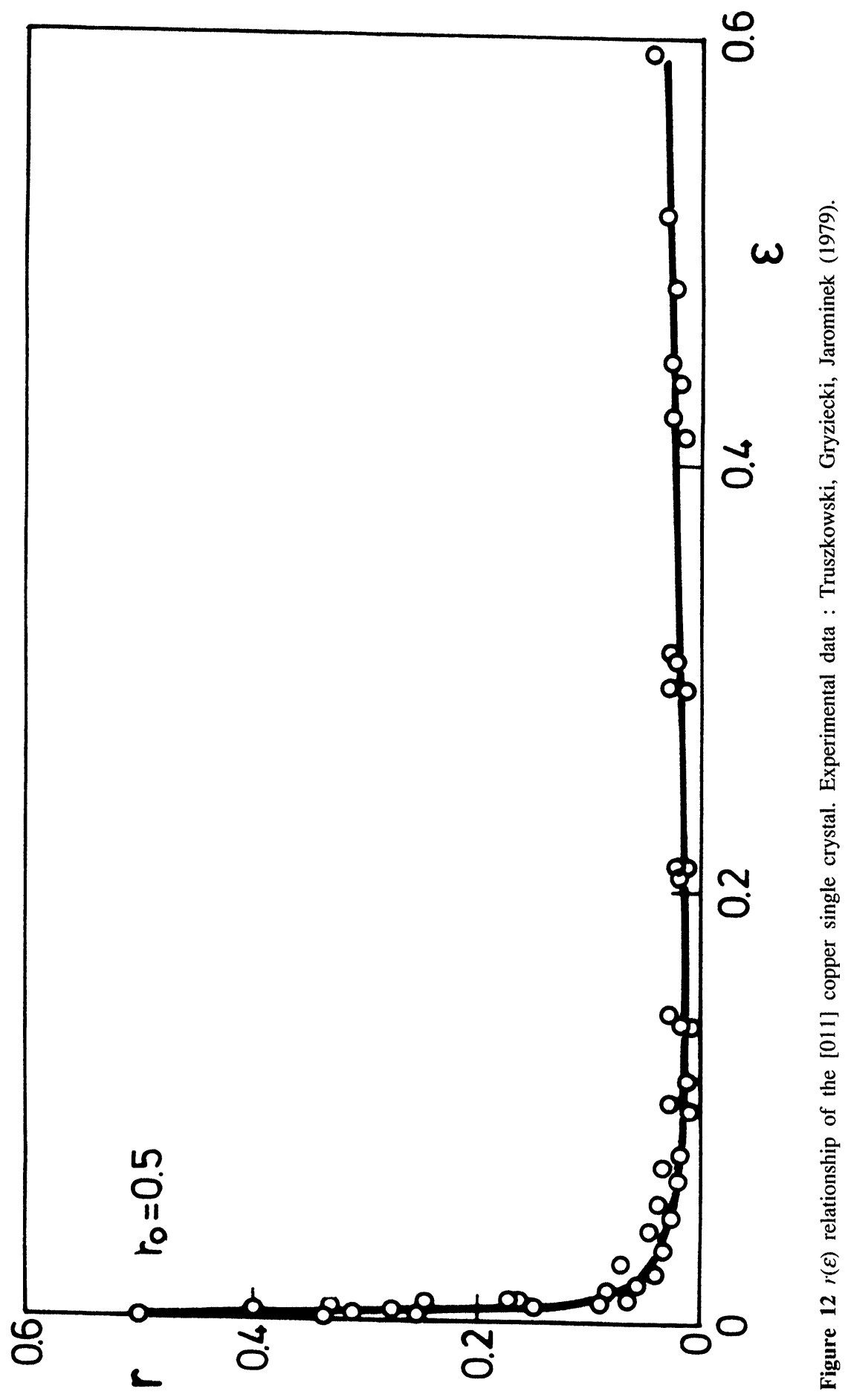


Krupkowski, A. and Kawiński, S. (1949). The Phenomenon of Anisotropy in Annealed Polycrystalline Metals. Journ. Inst. Metals, 75, 869-880.

Lankford, W. T., Snyder, S. C. and Bauscher, J. A. (1950). New Criteria for Predicting the Press Performance of Deep Drawing Sheets. Trans. Am. Soc. for Metals, 42, 1197-1225.

Truszkowski, W. (1956). Zagadnienie anizotropii zgniecionych metali polikrystalicznych. Arch. Hutn., $1,171-182$.

Truszkowski, W. und Latkowski, A. (1967). Über die Anisotropie des verformten vielkristallinen Nickels. Freiberger Forschungshefte, B123, Metallkunde, 61-75.

Truszkowski, W. and Jarominek, J. (1969). Plastic Anisotropy of Cold Rolled Copper. Arch. Hutn., 14, 309-326.

Truszkowski, W., Dutkiewicz, J. et Szpunar, J. (1970). Évolution de la texture et de l'anisotropie lors du laminage du laiton. Mém. Sci. Rev. Métallurg., 67, 355-366.

Truszkowski, W. et Jarominek, J. (1973). Essai de synthèse des recherches sur l'anisotropie plastique. Mém. Sci. Rev. Métallurg., 70, 433-443.

Truszkowski, W. (1976). Influence of Strain on the Plastic Strain Ratio in Cubic Metals. Metall. Trans., 7A, 327-329.

Truszkowski, W., Gryziecki, J. and Jarominek, J. (1979). Variation of Strain Ratio in Cube Plane of Copper. Metals Technology, 6, 439-441.

Truszkowski, W. i Wierzbiński, S. (1983). Izmenenie koefficienta plastičeskoj anizotropii monokristallov medi s orientacjej blizkoj [001] pri rastjazenii. Fizika Metallov i Metallovedenie, 56, 1195-1198.

Truszkowski, W. (1984). Quantitative Aspects of the Relation between Texture and Plastic Anisotropy. Proc. Intern. Conf. on Textures of Materials (ICOTOM - 7), Noordwijkerhout, 723-728.

Truszkowski, W. et Kloch, J. (1985). Modifications du coefficient d'anisotropie plastique en cours de déformation hétérogène. Matériaux et Techniques, E 17-E 20.

Truszkowski, W., Wierzbiński, S., Modrzejewski, A., Baczyński, J., Burchanov, G.S., Burov, I.V. and Cistjakov, O.D. (1987). Influence of Deviation from $\langle 001\rangle,\langle 011\rangle$ and $\langle 111\rangle$ Orientations on the Variation of Strain Ratio in Deformed Nickel Single Crystals. Arch. of Metall., 32, 165-170.

Truszkowski, W. (1988). The Impact of Texture in Single Crystals of FCC Metals on Mechanical Behaviour and Instability of Orientation. 8th Intern. Conf. on Textures of Materials (ICOTOM 8), Sante Fe, The Met. Soc., 537-542.

Truszkowski, W., Modrzejewski, A., Baczyński, J. (1989). Variation of the Strain Ratio in Tensile Tested <011> Brass Single Crystals. Bull. Pol. Ac.: Techn., 37, 471-479.

Truszkowski, W. and Kloch, J. (1989). Instability of Strain Ratio in Single Crystals Defined by the $r(\varepsilon)$ Function. Bull. Pol. Ac.: Techn., 37, 467-470. 